\title{
Metabolic syndrome according to different definitions in a rapidly developing country of the African region Clara Kelliny ${ }^{1}$, Julita William ${ }^{2}$, Walter Riesen ${ }^{3}$, Fred Paccaud ${ }^{1}$ and Pascal Bovet*1,2
}

\author{
Address: ${ }^{1}$ Institute of Social and Preventive Medicine (IUMSP), University Hospital Centre and University of Lausanne, rue du Bugnon 17, 1005 \\ Lausanne, Switzerland, ${ }^{2}$ Ministry of Health and Social Development, Victoria, Republic of Seychelles and ${ }^{3}$ Institute of Clinical Chemistry and \\ Hematology, Canton Hospital, St Gallen, Switzerland \\ Email: Clara Kelliny - clara.kelliny@unil.ch; Julita William - williamb913@hotmail.com; Walter Riesen - walter.riesen@ikch.ch; \\ Fred Paccaud - fred.paccaud@chuv.ch; Pascal Bovet* - pascal.bovet@chuv.ch \\ * Corresponding author
}

Published: 18 September 2008

Cardiovascular Diabetology 2008, 7:27 doi:10.1186/1475-2840-7-27

This article is available from: http://www.cardiab.com/content/7/1/27

(c) 2008 Kelliny et al; licensee BioMed Central Ltd.

This is an Open Access article distributed under the terms of the Creative Commons Attribution License (http://creativecommons.org/licenses/by/2.0), which permits unrestricted use, distribution, and reproduction in any medium, provided the original work is properly cited.
Received: 13 July 2008

Accepted: 18 September 2008

\begin{abstract}
Aims: We examined, in a country of the African region, i) the prevalence of the metabolic syndrome (MetS) according to three definitions (ATP, WHO and IDF); ii) the distribution of the MetS criteria; iii) the level of agreement between these three definitions and iv) we also examined these issues upon exclusion of people with diabetes.
\end{abstract}

Methods: We conducted an examination survey on a sample representative of the general population aged 25-64 years in the Seychelles (Indian Ocean, African region), attended by 1255 participants (participation rate of $80.3 \%$ ).

Results: The prevalence of MetS increased markedly with age. According to the ATP, WHO and IDF definitions, the prevalence of MetS was, respectively, $24.0 \%, 25.0 \%, 25.1 \%$ in men and $32.2 \%$, $24.6 \%, 35.4 \%$ in women. Approximately $80 \%$ of participants with diabetes also had MetS and the prevalence of MetS was approximately $7 \%$ lower upon exclusion of diabetic individuals. High blood pressure and adiposity were the criteria found most frequently among MetS holders irrespective of the MetS definitions. Among people with MetS based on any of the three definitions, $78 \%$ met both ATP and IDF criteria, $67 \%$ both WHO and IDF criteria, $54 \%$ both WHO and ATP criteria and only $37 \%$ met all three definitions.

Conclusion: We identified a high prevalence of MetS in this population in epidemiological transition. The prevalence of MetS decreased by approximately $32 \%$ upon exclusion of persons with diabetes. Because of limited agreement between the MetS definitions, the fairly similar proportions of MetS based on any of the three MetS definitions classified, to a substantial extent, different subjects as having MetS.

\section{Introduction}

The metabolic syndrome (MetS) represents a cluster of metabolic risk factors that co-occur to a greater degree than predicted by chance. While it is clear that MetS is associated with cardiovascular disease and diabetes [1], it is still controversial whether MetS adds predictive value 
that goes beyond that of its single constituents $[1,2]$. Insulin resistance was initially the main focus of MetS, but adiposity, sedentary lifestyle, dietary and genetic factors have also received much attention when considering the pathogenesis of MetS [3]. High prevalence of MetS has often been documented in developed countries and increasingly so in developing countries [4-17], although data in developing countries and particularly in the Sub-Saharan region remain scarce [18].

Over the past decade, several definitions of MetS have been coined. In this paper, we consider three major definitions: i) the definition of the World Health Organization (WHO), issued in 1998 [19]; ii) the definition of the National Cholesterol Education Program Adult Treatment Panel III (ATP), issued in 2001 and updated in 2004 and 2005 [20], and the definition of the International Diabetes Federation (IDF), introduced in 2005 [21]. These definitions agree that the core criteria of MetS include: i) blood glucose impairment (hyperglycemia and/or insulin resistance), ii) excess abdominal/body fat (increased waist and/or obesity), iii) dyslipidemia (low HDL-cholesterol and/or high triglycerides), and iv) elevated blood pressure. However, criteria and cut-off values differ between these definitions, implying that different definitions may identify different people, as documented in the few studies that have addressed this question $[4,7,8,22]$.

There is some controversy over whether identification of MetS should exclude people with diabetes since diabetes alone is sufficient to define high cardiovascular risk and MetS has been used as a tool to predict diabetes $[2,23]$.

This analysis had four main objectives. First, we evaluated the prevalence of MetS according to three MetS definitions in the Seychelles, a rapidly developing country of the African region. Second, we examined the distribution of the MetS criteria according to the different MetS definitions. Third, we compared the level of agreement between the different MetS definitions and their ability to identify the same subjects. Fourth, we examined how the prevalence of MetS and the other end points differed upon restricting assessment of the metabolic syndrome to the non-diabetic population.

\section{Methods}

\section{Survey procedures}

The Republic of Seychelles is a group of islands in the Indian Ocean (African region) situated approximately $1800 \mathrm{~km}$ east of Kenya. A large majority of the population is of African descent. HIV and cardiovascular diseases account for approximately $1 \%$ and $38 \%$ of total mortality, respectively [24]. High prevalence of several cardiovascular risk factors including obesity, hypertension and diabe- tes has been documented as early as in 1989 [25] and in 2004 [26-28].

A population-based survey of cardiovascular risk factors was conducted in 2004 under the auspices of the Ministry of Health of the Republic of Seychelles (Seychelles Heart Study III). Methods and main results have been published previously [26-28]. Briefly, the sampling frame consisted of a sex and age stratified random sample of the entire population aged 25-64 years. Eligible participants were selected from computerized data of a national population census in 2002, thereafter updated by the civil status authorities. The survey was approved by the Ministry of Health after technical and ethical reviews. Eligible participants were invited by a letter to attend the survey at study centers on specified dates. They were free to participate and gave written informed consent.

Blood pressure was defined as the average of the last two of three measurements with a mercury sphygmomanometer taken at intervals longer than 2 minutes after the participants had been sitting for at least 30 minutes. Weight was measured with precision electronic scales (Seca, Hamburg) and height was measured with a fixed stadiometer.

Fasting blood was taken between 7:00 and 10:00 am. Serum was obtained within 2 hours of blood collection and immediately frozen to $-20^{\circ} \mathrm{C}$. Blood lipids were measured with standard methods. Fasting blood glucose (FBG) was analyzed immediately with a point-of-care analyzer (Cholestec LDX, Hayward, USA). If glucose was $\geq 5.6 \mathrm{mmol} / \mathrm{l}$ and the participant was not aware of having diabetes, an additional capillary measurement was performed within 10 minutes with a glucometer that adjusts readings to plasma values (Ascencia Elite, Bayer) and the average of the two readings was considered [27]. An oral glucose tolerance test (OGTT) was performed on all people who had FBG between 5.6 and $7.0 \mathrm{mmol} / \mathrm{L}$ but had never been diagnosed with diabetes. Fasting serum insulin was measured using commercial RIA kits (LINCO Research Inc, Missouri, USA). Microalbuminuria was measured with a semi-quantitative method using a Clinitek Status analyzer (Bayer, Leverkussen, Germany) [28].

\section{Definitions of the metabolic syndrome}

The prevalence of MetS was calculated according to the standard criteria detailed in Table 1. For the WHO definition, we defined insulin resistance as the upper quartile of the homeostasis model assessment of insulin resistance (HOMA-IR), calculated as [fasting serum insulin level $(\mathrm{microU} / \mathrm{ml}) \times$ fasting blood glucose level $(\mathrm{mmol} / \mathrm{L})] /$ 22.5 [29], which has been shown to be a reliable estimate of insulin resistance both among diabetic and non diabetic subjects $[30,31]$. For the IDF definition, we used ethnic-specific cutoff values for waist circumference, i.e. the 
Table I: Criteria for three definitions of the metabolic syndrome (WHO, ATP, IDF)

\begin{tabular}{|c|c|c|c|}
\hline & WHO 1998 & NCEP ATP III 2005 & IDF 2005 \\
\hline & $\begin{array}{l}\text { Diabetes, IFG, IGT or insulin } \\
\text { resistance I } \\
\text { plus two or more of the remaining } \\
\text { criteria. }\end{array}$ & Any three or more criteria. & $\begin{array}{l}\text { Central obesity } \\
\text { plus two or more of the remaining } \\
\text { criteria. }\end{array}$ \\
\hline I. Adiposity & $\begin{array}{l}\text { Waist } / \text { hip ratio }>0.9(\mathrm{M}),>0.85(\mathrm{~F}) \\
\text { or } \mathrm{BMI}>30 \mathrm{~kg} / \mathrm{m}^{2}\end{array}$ & $W C \geq 102 \mathrm{~cm}(\mathrm{M}), \geq 88 \mathrm{~cm}(\mathrm{~F})$ & $W C \geq 94 \mathrm{~cm}(\mathrm{M}), \geq 80 \mathrm{~cm}(\mathrm{~F})^{2}$ \\
\hline 2. Raised blood pressure & $\mathrm{BP} \geq 140 / 90 \mathrm{mmHg}$ or medication & \multicolumn{2}{|c|}{$\mathrm{BP} \geq 130 / 85 \mathrm{mmHg}$ or medication } \\
\hline \multirow[t]{2}{*}{ 3. Dyslipidemia } & $\begin{array}{l}\mathrm{TG} \geq 1.7 \mathrm{mmol} / \mathrm{l} \text { or } \mathrm{HDL}<0.9 \mathrm{mmol} / \\
\mathrm{L}(\mathrm{M}),<1.0 \mathrm{mmol} / \mathrm{L}(\mathrm{F})\end{array}$ & \multicolumn{2}{|c|}{$\mathrm{TG} \geq 1.7 \mathrm{mmol} / \mathrm{L}$ or medication ${ }^{3}$} \\
\hline & & \multicolumn{2}{|c|}{ HDL-C $<1.03 \mathrm{mmol} / \mathrm{L}(\mathrm{M})$ or $<1.29 \mathrm{mmol} / \mathrm{L}(\mathrm{F})$ or medication 3} \\
\hline $\begin{array}{l}\text { 4. Impaired glucose regulation } \\
\text { (dysglycemia) }\end{array}$ & $\begin{array}{l}\text { Diabetes, IFG }(\mathrm{FBG} \geq 6.1 \mathrm{mmol} / \mathrm{I}) \text {, } \\
\text { IGT, or insulin resistance }\end{array}$ & $\mathrm{FBG} \geq 5.6 \mathrm{mmol} / \mathrm{L}^{4}$ & $\begin{array}{l}\mathrm{FBG} \geq 5.6 \mathrm{mmol} / \mathrm{L} \text { or previously } \\
\text { diagnosed diabetes }\end{array}$ \\
\hline 5. Microalbuminuria & $\begin{array}{l}\text { Microalbuminuria: albumin } \geq 20 \mu g / \\
\mathrm{min} \text { or albumin/creatinine ratio } \\
(A C R) \geq 30 \mathrm{mg} / \mathrm{g}\end{array}$ & & \\
\hline
\end{tabular}

WHO: World Health Organization [19]; ATP: National Cholesterol Education Program-Adult Treatment Panel III [20]; IDF: International Diabetes Federation [2I].

BMI: body mass index; BP: blood pressure; HDL-C: high density lipoprotein cholesterol; FBG: fasting blood glucose; IFG: impaired fasting glucose; IGT: impaired glucose tolerance; TG: triglycerides; WC: waist circumference.

1 Glucose uptake below lowest quartile under hyperinsulinemic euglycemic conditions for background population under investigation.

${ }^{2}$ Cut off for Sub Saharan Africans, Europids, and Eastern Mediterranean and Middle Eastern populations; $\geq 90 \mathrm{~cm}(\mathrm{M}), \geq 80 \mathrm{~cm}(\mathrm{~F})$ for South Asians, Chinese, Japanese, and ethnic South and Central Americans [2I].

${ }^{3}$ Specific treatment for hypertriglyceridemia or low HDL-cholesterol such as fibrate or nicotinic acid.

${ }^{4}$ This cut off was lowered from $\geq 6.1 \mathrm{mmol} / \mathrm{L}$ to $\geq 5.6 \mathrm{mmol} / \mathrm{l}$ in $2005[20]$.

same criteria for Europid and Sub-Saharan subjects ( $\geq 94$ $\mathrm{cm}$ for men and $\geq 80 \mathrm{~cm}$ for women) [21] and, by extension, for people of 'mixed' descent, and $\geq 90 \mathrm{~cm}$ for men and $\geq 80 \mathrm{~cm}$ for women of the $4 \%$ of participants considered as 'Indian' or 'Chinese'. Information on treatment for dyslipidemia was not available at an individual level and we assumed that no one was under treatment, consistent with the very low number of people treated in Seychelles for dyslipidemia.

\section{Analysis}

Analysis was performed with Stata 9.0. All analyses were standardized for age using the new WHO standard population [32]. Agreement between the three MetS definitions was determined using the Kappa statistic ( $\kappa)$. We graphed Venn diagrams for agreement between different definitions of MetS using the MATLAB 7.6 software, which allows representing areas proportionally to the corresponding numbers of cases. $P$ values $<0.05$ were considered statistically significant.

\section{Results}

\section{Characteristics of the population}

From the 1563 eligible participants, 1255 participated in the survey (80.3\% participation rate) and 1218 had all necessary measurements to evaluate MetS according the three considered definitions and were included in this study. The distribution of selected risk factors and MetS criteria is presented in Table 2.

\section{Prevalence of the metabolic syndrome}

Figure 1 shows the prevalence of MetS according to the definitions by ATP, WHO and IDF. The age-standardized prevalence of MetS in the population aged 25-64 years was $28.1 \%$ (95\% CI: $25.6-30.7), 24.8 \%$ (22.4-27.2) and $30.3 \%(27.7-32.9)$, respectively. At age $35-64$, the agestandardized prevalence was, respectively, 36.7\% (33.6$39.7), 32.4 \%(29.5-35.4)$ and 39\% (35.9-42.1) overall; $31.9 \%(27.5-36.4), 33.4 \%(28.9-37.9)$ and $33.5 \%$ (29.0-38.0) among men; and 41.4\% (37.1-45.6), 31.4\% (27.5-35.4) and 44.4\% (40.2-48.7), among women.

The prevalence of MetS increased markedly with age for both genders. However, the prevalence of MetS using the ATP definition was highest at age 45-54 for men. With regards to gender, the prevalence was significantly greater in women than in men according to the ATP and IDF definitions while the prevalence was similar in both genders using the WHO definition.

A large proportion of people with diabetes also had MetS: $66.8 \%, 85.5 \%, 74 \%$ among men and $87.1 \%, 79.7 \%, 93 \%$ among women, according to the ATP, WHO and IDF definitions, respectively. However, this proportion was smaller among men at age 45-64 years than in the other age categories (Figure 1).

Upon exclusion of individuals with diabetes, the agestandardized prevalence of MetS at age 25-64 years was 
Table 2: Age-standardized distribution of selected risk factors in the population aged 25-64 years

\begin{tabular}{|c|c|c|c|c|c|c|c|}
\hline & & All & SD & Men & SD & Women & SD \\
\hline $\mathrm{N}$ & & 1218 & & 548 & & 679 & \\
\hline Age (years) & & 42.0 & 10.8 & 42.1 & 10.7 & 41.9 & 11.0 \\
\hline \multicolumn{8}{|l|}{ Anthropometric parameters } \\
\hline BMI $\left(\mathrm{kg} / \mathrm{m}^{2}\right)$ & & 26.9 & 5.7 & 25.5 & 4.7 & 28.3 & 6.3 \\
\hline Waist circumference $(\mathrm{cm})$ & & 89.5 & 13.0 & 88.9 & 11.9 & 90.2 & 14.1 \\
\hline \multirow[t]{2}{*}{ Adiposity ATP (\%) } & $W C \geq 102 \mathrm{~cm}(M), \geq 88 \mathrm{~cm}(\mathrm{~W})$ & 35.2 & & 14.0 & & 56.0 & \\
\hline & WHR $>0.9(\mathrm{M}),>0.85(\mathrm{~W})$ or BMI & 61.5 & & 50.7 & & 72.1 & \\
\hline Adiposity WHO (\%) & $>30$ & & & & & & \\
\hline Adiposity IDF (\%) & $W C \geq 94 \mathrm{~cm}(M), \geq 80 \mathrm{~cm}(\mathrm{~W})$ & 55.8 & & 35.8 & & 75.6 & \\
\hline \multicolumn{8}{|l|}{ Blood pressure } \\
\hline Systolic BP (mmHg) & & 127.7 & 18.6 & 131.0 & 17.7 & 124.4 & 18.8 \\
\hline Diastolic BP (mmHg) & & 83.3 & 11.8 & 85.5 & 11.7 & 81.2 & 11.5 \\
\hline Raised BP - ATP/IDF (\%) & $\mathrm{BP} \geq 130 / 85 \mathrm{mmHg}$ or medication & 51.7 & & 57.0 & & 46.4 & \\
\hline Raised BP - WHO (\%) & $\mathrm{BP} \geq \mathrm{I} 40 / 90 \mathrm{mmHg}$ or medication & 39.5 & & 43.3 & & 35.7 & \\
\hline \multicolumn{8}{|l|}{ Glucose regulation } \\
\hline Fasting glucose (mmol/L) & & 5.9 & 2.0 & 6.0 & 2.1 & 5.7 & 1.8 \\
\hline Insulin (pmol/L) & & 14.8 & 12.1 & 13.6 & 11.6 & 16.1 & 12.4 \\
\hline Impaired fasting glucose (\%) & & |4.1 & & 20.5 & & 7.7 & \\
\hline Impaired glucose tolerance (\%) & & 12.6 & & 13.9 & & 11.2 & \\
\hline Diabetes (\%) & & 10.7 & & 9.7 & & 11.7 & \\
\hline Dysglycemia ATP (\%) & $\mathrm{FBG} \geq 5.6 \mathrm{mmol} / \mathrm{l}$ & 33.3 & & 40.0 & & 26.7 & \\
\hline Dysglycemia WHO (\%) & DM, IFG, IGT or insulin resistance & 36.1 & & 35.5 & & 36.7 & \\
\hline Dysglycemia IDF (\%) & $\mathrm{FBG} \geq 5.6 \mathrm{mmol} / \mathrm{l}$ or history of DM & 33.9 & & 40.4 & & 27.5 & \\
\hline \multicolumn{8}{|l|}{ Blood lipids } \\
\hline Total cholesterol (mmol/L) & & 5.4 & 1.3 & 5.4 & 1.3 & 5.4 & 1.3 \\
\hline HDL cholesterol (mmol/L) & & 1.4 & 0.5 & 1.4 & 0.5 & 1.4 & 0.4 \\
\hline Triglyceride level (mmol/L) & & 1.0 & 0.8 & 1.2 & 1.0 & 0.9 & 0.5 \\
\hline Hypertriglyceridemia ATP/IDF (\%) & $\mathrm{TG} \geq 1.7 \mathrm{mmol} / \mathrm{l}$ or medication & 12.6 & & 17.4 & & 7.8 & \\
\hline Low HDL-C ATP/IDF (\%) & HDLC $<1.03(\mathrm{M}) ;<1.29(\mathrm{~W})$ & 38.2 & & 28.6 & & 47.8 & \\
\hline Dyslipidemia WHO (\%) & $\mathrm{TG} \geq 1.7$ or $\mathrm{HDL}<0.9(\mathrm{M}),<1.0(\mathrm{~W}))$ & 23.8 & & 27.3 & & 20.3 & \\
\hline Microalbuminuria & & 11.9 & & 11.2 & & 12.6 & \\
\hline Regular cigarette smoking (\%) & & 17.3 & & 30.9 & & 3.7 & \\
\hline Alcohol (mL/day) & & 22.3 & 62.0 & 41.1 & 82.8 & 3.6 & 12.8 \\
\hline
\end{tabular}

Mean \pm SD (standard deviation) or proportion; BMI: body mass index; WC: waist circumference; WHR: waist to hip ratio; BP: blood pressure; DM: diabetes; IFG: impaired fasting glucose; IGT: impaired glucose tolerance; M: men; W: women. HDL-cholesterol and triglyceride: units in mmol/L.

$22.2 \%(19.6-24.7)$ according to ATP, $17.9 \%(15.6-20.2)$ according to WHO and $23.8 \%(21.2-26.4)$ according to IDF. Using the EGIR definition of MetS [33], a modified version of the WHO definition that applies to non-diabetic subjects, the age-standardized prevalence of MetS was $15.1 \%$ (95\% CI: 12.9-17.3); 14.1\% (10.9-17.2) among men and 16.2\% (13.1-19.2) among women.

Upon exclusion of persons with diabetes, the prevalence (in absolute terms) of MetS decreased by $4.6 \%, 6.5 \%$, $5.3 \%$ in men and $7.3 \%, 7.3 \%, 7.7 \%$ in women according to the ATP, WHO and IDF definitions, respectively. This corresponds to a relative decrease in the prevalence of MetS of approximately 32\%. At the age of 35-64 years, the decrease in prevalence (in absolute terms) was respectively $5.8 \%, 8.6 \%, 6.7 \%$ in men and $7.8 \%, 6.7 \%, 8.8 \%$ in women (a relative decrease of approximately $34 \%$ ). The reduction in prevalence of MetS upon exclusion of sub- jects with diabetes was slightly greater when using the WHO definition of MetS than the other two definitions.

\section{Distribution of criteria of the metabolic syndrome}

High blood pressure, obesity and impaired glucose regulation were the most prevalent criteria for all MetS definitions (Figure 2). Hypertriglyceridemia was found more often in men than in women, while the opposite was true for low HDL-cholesterol. This criteria distribution was similar across age categories.

\section{Agreement between different definitions of the metabolic syndrome}

Figure 3 shows the level of agreement between the three MetS definitions. 37\% of all subjects aged 25-64 had MetS as based on any of the three MetS definitions. Among these MetS-holders, 69\% had MetS based on ATP and IDF, 50\% based on ATP and WHO, 53\% based on 

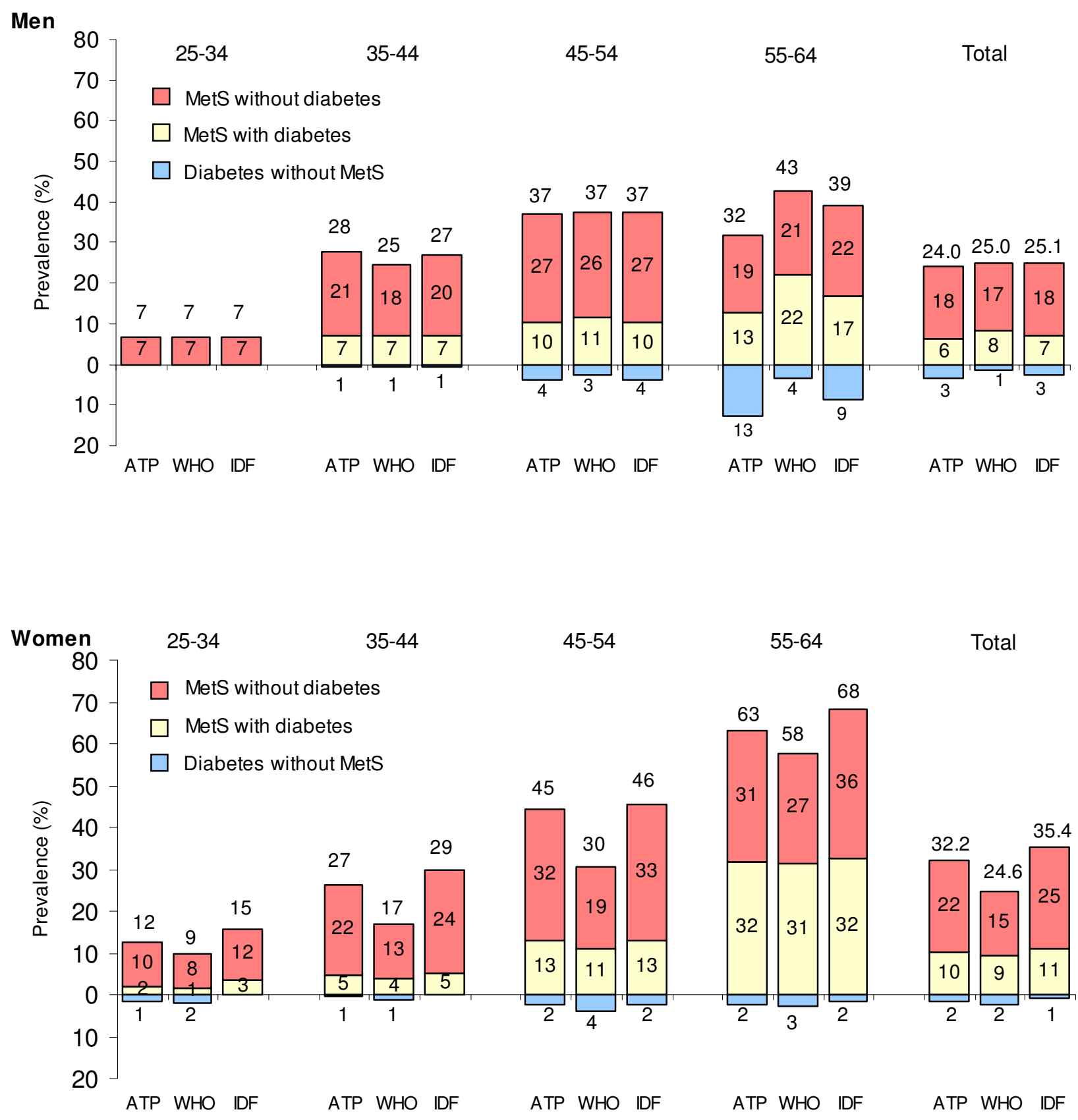

Figure I

Prevalence of the metabolic syndrome according to sex, age category, diabetic status and different definitions of the metabolic syndrome. 


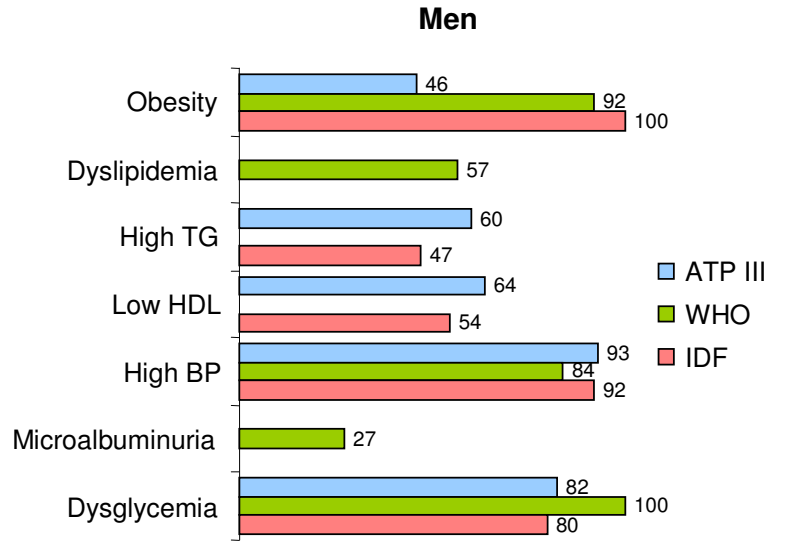

\section{Figure 2 \\ Proportion of subjects with the metabolic syndrome who have selected criteria according to sex and different definitions of the metabolic syndrome (TG: triglyceride; HDL: HDL-cholesterol; BP: blood pressure).}

WHO and IDF; and $48 \%$ had MetS based on the three definitions. With reference to the total population, MetS was diagnosed in $28 \%$ based on ATP, $25 \%$ based on WHO and $30 \%$ based on IDF. Based on Figure 3, one can calculate that 25\% were diagnosed with MetS based on ATP and IDF, $20 \%$ based on WHO and IDF, $19 \%$ based on WHO and ATP; and $18 \%$ based on all three definitions.

Within the non-diabetic population, 30\% had MetS based on either the WHO, ATP or IDF definitions, out of which $37 \%$ had MetS based on all three definitions.

The kappa statistic was 0.82 for ATP-IDF, 0.61 for IDFWHO and 0.59 for WHO-ATP, respectively $0.81,0.53$ and 0.51 , upon exclusion of people with diabetes. The higher kappa statistic for ATP-IDF versus either IDF-WHO or WHO-ATP was found irrespective of gender and age (Table 3).

In order to examine possible causes of fairly low agreement between the MetS definitions, we compared agreement between the criteria of the three MetS definitions in the entire population (Table 4). The largest disagreement was found for adiposity. As many as $70 \%$ of the total population fulfilled the criteria for adiposity according to either the ATP, WHO or IDF definitions of MetS (i.e. based on BMI, waist circumference or waist to hip ratio). However, the prevalence of the adiposity criterion varied largely according to the different MetS definitions: $35.2 \%$ according to ATP, $61.5 \%$ according to WHO, and $55.8 \%$ according to IDF. Out of those who qualified for adiposity according to any MetS definitions, only $48 \%$ met all three definitions. With regards to the other MetS criteria, the
WHO definition disagreed with the other two definitions of MetS (ATP and IDF) in identifying people with dyslipidemia and to a lesser extent, with impaired glucose regulation. However, these criteria are less prevalent in the population than adiposity (Table 2), which results in less impact on MetS classification.

\section{Discussion}

The main findings of the study are as follows: i) the prevalence of MetS was high in this population of East Africa regardless of which MetS definition was used; ii) the prevalence of MetS decreased by approximately one third upon exclusion of persons with diabetes; and iii) agreement between different MetS definitions was limited and consequently, the similar prevalence of MetS according to either MetS definition actually identified, to a substantial extent, different subjects as having MetS.

In our study, the prevalence of MetS at the age of 25-64 years ranged between $25 \%$ and $30 \%$. This is much higher than the $8 \%$ reported in Cameroon [18], which is, to the best of our knowledge, the only other population based published assessment of the prevalence of MetS in SubSaharan Africa. A previous study in the Seychelles [34] found that plasma aldosterone, but not plasma renin activity, was associated with MetS. However this study included participants from families with hypertension and was therefore not intended to assess the prevalence of MetS in the general population. In order to compare the prevalence in Seychelles with that in other countries, we compiled findings of selected population-based studies that had assessed MetS according to at least two MetS definitions, and included participants of 35-64 years (Table 


\section{Total population}

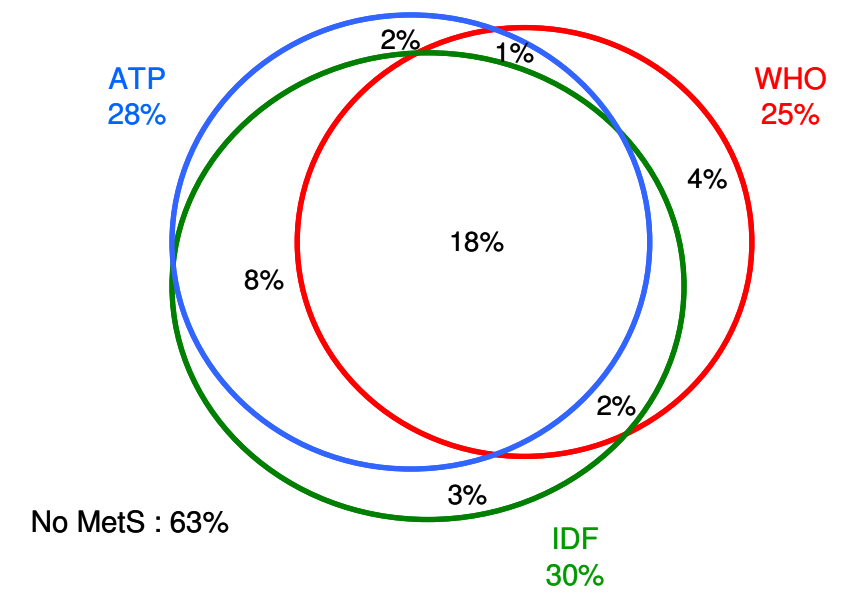

Men

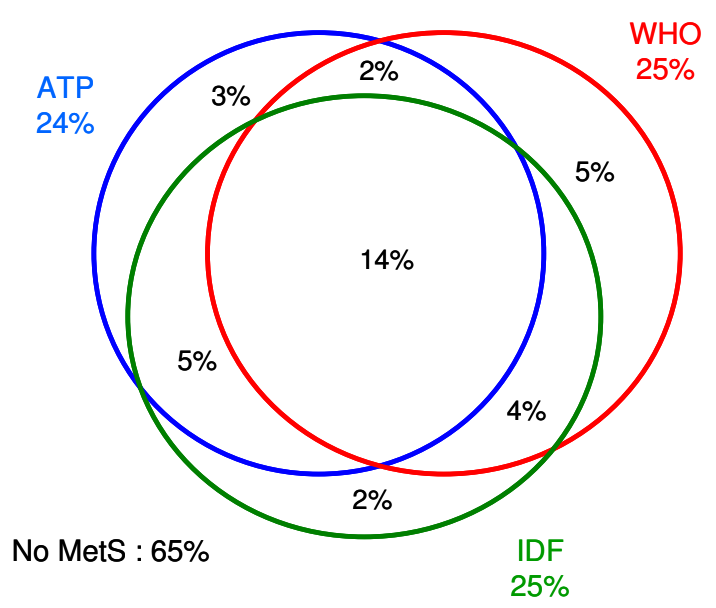

Women

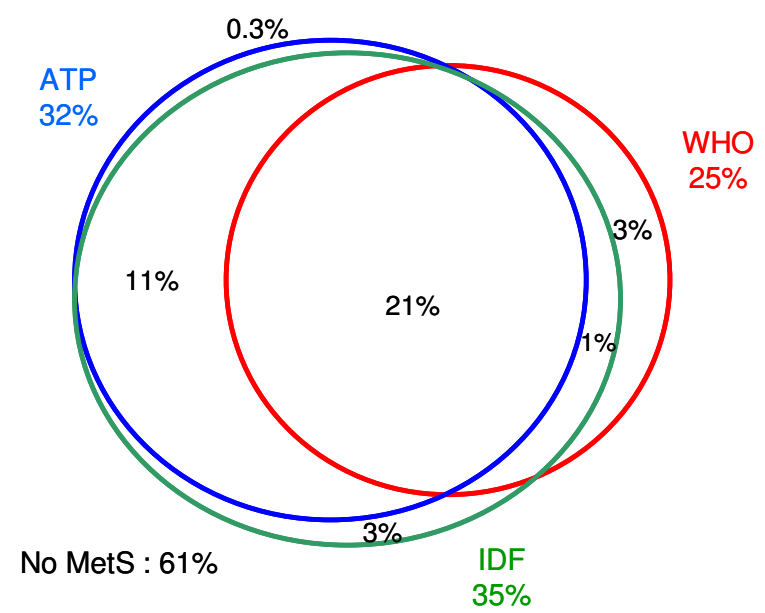

Figure 3

Agreement between three definitions of the metabolic syndrome (all prevalence estimates are expressed as percent of the general population).

$5)$. The prevalence of MetS was similar in Seychelles as in many Western countries [9-11,13] and in urban India [15]. The prevalence of MetS in Seychelles was lower than in certain countries, e.g. USA [5], Portugal [8], Samoa [13], Turkey [7] and Tunisia [4] but higher than in Mexico [6] and several Asian countries e.g. Korea [14], Japan [13] and China [17]. The high prevalence of MetS in Seychelles is consistent with high prevalence of several MetS criteria, particularly overweight, hypertension, dyslipidemia and diabetes [25-27].
The prevalence of MetS in Seychelles did not differ markedly according to the three different MetS definitions, consistent with observations in several populations $[5,9,10,14,17]$, but not in others $[4-7,12,13]$. However, the prevalence of MetS in Seychelles was moderately higher according to IDF than ATP or WHO, a finding reported in most studies that had assessed this issue $[4,5,7,8,10-13,15]$, except for a few $[16,17]$. It has frequently been reported that the prevalence of MetS according to the WHO definition is generally greater among men 
Table 3: Agreement (kappa values) between different definitions of the metabolic syndrome in the population with and without exclusion of diabetic persons

\begin{tabular}{|c|c|c|c|c|c|c|}
\hline & \multicolumn{2}{|c|}{ ATP-IDF } & \multicolumn{2}{|c|}{ IDF-WHO } & \multicolumn{2}{|c|}{ WHO-ATP } \\
\hline & All & Non-diabetic & All & Non-diabetic & All & Non-diabetic \\
\hline All & 0.82 & 0.81 & 0.61 & 0.53 & 0.59 & 0.51 \\
\hline Men & 0.71 & 0.67 & 0.62 & 0.55 & 0.56 & 0.48 \\
\hline Women & 0.92 & 0.91 & 0.60 & 0.52 & 0.63 & 0.53 \\
\hline Age $25-44$ years & 0.79 & 0.76 & 0.49 & 0.42 & 0.52 & 0.44 \\
\hline Age 45-64 years & 0.83 & 0.83 & 0.64 & 0.58 & 0.58 & 0.53 \\
\hline
\end{tabular}

than women [35] but we did not observe such a gender difference in Seychelles.

The level of agreement between the different definitions of MetS was not optimal in our study. Less than half of the individuals labeled as having MetS according to any of the three considered definitions were classified as MetS-holders according to all three definitions. We found that agreement between the MetS definitions was better for IDF-ATP than for WHO-IDF and WHO-ATP. This finding is consistent with data in several populations on several continents $[7,8,10,13,15]$. This difference is expected since MetS is based on the same criteria according to IDF and ATP, except for the adiposity criterion. Agreement between the MetS definitions was generally better among women than men in Seychelles, consistent with previous reports $[5,8,14]$. This may relate to the fact, at least in Seychelles, that the prevalence of the adiposity criterion was virtually identical and close to $100 \%$ across the three MetS definitions among women with MetS, but was lower and largely different between MetS definitions in men.

Table 4: Kappa values between different criteria of different definitions of the metabolic syndrome

\begin{tabular}{lccc}
\hline & ATP-IDF & IDF-WHO & WHO-ATP \\
\hline Total population & & & \\
Obesity & 0.60 & 0.55 & 0.44 \\
Raised blood pressure & 1.00 & 0.76 & 0.76 \\
Impaired glucose regulation & 0.99 & 0.67 & 0.66 \\
Hypertriglyceridemia & 1.00 & 1.00 & 1.00 \\
Low HDL-cholesterol & 1.00 & 0.50 & 0.50 \\
Men & & & \\
Obesity & 0.45 & 0.55 & 0.27 \\
Raised blood pressure & 1.00 & 0.73 & 0.73 \\
Impaired glucose regulation & 0.99 & 0.65 & 0.64 \\
Hypertriglyceridemia & 1.00 & 1.00 & 1.00 \\
Low HDL-cholesterol & 1.00 & 0.69 & 0.69 \\
Women & & & \\
Obesity & 0.58 & 0.45 & 0.50 \\
Raised blood pressure & 1.00 & 0.78 & 0.78 \\
Impaired glucose regulation & 0.98 & 0.70 & 0.68 \\
Hypertriglyceridemia & 1.00 & 1.00 & 1.00 \\
Low HDL-cholesterol & 1.00 & 0.36 & 0.36 \\
& & & \\
\hline
\end{tabular}

Hence, we found a similar prevalence of MetS in Seychelles according to the three different MetS definitions but the different MetS definitions actually identified, to a substantial extent, different individuals. Poor agreement between MetS definitions has several clinical and epidemiological implications $[16,22]$. First, it is questionable to directly compare the burden of MetS between populations based on different definitions. Second, it remains unclear whether cardiometabolic outcomes differ if MetS is defined according to one, two or three MetS definitions. Few studies have assessed the predictive value of MetS when MetS is based on more than one definition [36]. The study of Benetos et al [36] showed that the prevalence of MetS was markedly higher when MetS was based on either the IDF or ATP (2005 version) definitions as compared to the 2001 ATP definition alone, but only individuals with MetS according to the 2001 ATP definition had a higher risk of all-cause and cardiovascular mortality.

The prevalence of MetS restricted to the non-diabetic population (e.g. according to the EGIR definition, which is a definition of MetS that explicitly excludes diabetes [33]) was similar in Seychelles as in several countries in Europe [37-39] and higher than in Japan and Korea [13]. In the Seychelles, about one third of the adults who had MetS also had diabetes and, inversely, most adults who had diabetes also had MetS. Hence, the prevalence of MetS, according to either the ATP, WHO and IDF definitions, decreased markedly (a relative decrease of approximately one third) upon exclusion of persons with diabetes. This difference is larger than reported in other studies $[6,13]$. We also observed that this decrease in the prevalence of MetS upon exclusion of diabetes was larger according to the WHO definition compared to the ATP and IDF definitions, which has also been observed in Samoa [13] and Mexico [6].

The issue of whether MetS should be defined upon exclusion of diabetes is relevant to both clinical practice and epidemiology. It has been argued that MetS status does not add incremental information for cardiovascular management of diabetic individuals [23], since diabetes alone defines high cardiovascular risk. For the same reason, it 
Table 5: Prevalence of the metabolic syndrome in the Seychelles and in other populations, according to different definitions of the metabolic syndrome

\begin{tabular}{|c|c|c|c|c|c|c|c|c|c|c|c|c|}
\hline \multirow[b]{2}{*}{ Place } & \multirow[b]{2}{*}{ Population } & \multirow[b]{2}{*}{ Age } & \multirow[b]{2}{*}{$\mathrm{n}$} & \multicolumn{3}{|c|}{ ATP } & \multicolumn{3}{|c|}{ WHO } & \multicolumn{3}{|c|}{ IDF } \\
\hline & & & & M & W & All & M & W & All & M & W & All \\
\hline \multicolumn{13}{|l|}{ Africa } \\
\hline Seychelles & Nation wide & $25-64$ & 1218 & 24 & 32 & 28 & 25 & 25 & 25 & 25 & 35 & 30 \\
\hline Tunisia [3] & City of Tunis & $\geq 40$ & 863 & 15 & 31 & 24 & 26 & 31 & 29 & 30 & 56 & 46 \\
\hline Cameroon[17] & City of Yaoundé and three rural villages & $24-74$ & 1573 & $<0.5$ & $<0.2$ & - & $<8$ & $<6$ & - & $<2$ & $<2$ & - \\
\hline \multicolumn{13}{|l|}{ Americas } \\
\hline USA [4] & NHANES 1999-2002 & $\geq 20$ & 3601 & 34 & 35 & 35 & - & - & - & 41 & 37 & 39 \\
\hline Mexico [5] & Nation wide & $20-69$ & 2158 & 29 & 25 & 27 & 13 & 14 & 14 & - & - & - \\
\hline \multicolumn{13}{|l|}{ Europe } \\
\hline Turkey [6] & Istanbul (urban) and Kayseri (rural) & $>20$ & 1568 & 41 & 43 & 38 & 23 & 18 & 19 & 46 & 48 & 42 \\
\hline Portugal [7] & City of Porto & $18-92$ & 1433 & 32 & 40 & 37 & 30 & 24 & 26 & 38 & 44 & 42 \\
\hline Canary Island [8] & Nation wide & $>30$ & 1030 & 28 & 29 & 28 & 33 & 24 & 28 & - & - & - \\
\hline Norway [9] & North-Trondelag Health Study (HUNT 2) & $20-89$ & 10,206 & 27 & 25 & 26 & - & - & - & 29 & 30 & 30 \\
\hline Germany [10] & PROCAM study & $16-65$ & $7|3|$ & 25 & 18 & - & - & - & - & 32 & 23 & - \\
\hline Greece [II] & Representative sample of Greek adults & $>18$ & 9,669 & 25 & 24 & 25 & - & - & - & - & - & 43 \\
\hline \multicolumn{13}{|c|}{ 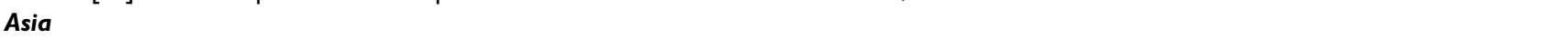 } \\
\hline Samoa $[12]$ & Population-based (DETECT 2) & $>35$ & 1344 & 39 & 57 & - & 22 & 26 & - & 45 & 60 & - \\
\hline Australia [12] & Population-based (DETECT 2) & $>35$ & 9409 & 36 & 28 & - & 26 & 18 & - & 42 & 33 & - \\
\hline Korea [13] & Korean National Health and Nutrition Survey & $\geq 20$ & 6601 & 18 & 21 & 19 & - & - & - & 15 & 24 & 20 \\
\hline India $[14]$ & City of Chennai & $\geq 20$ & 2350 & 17 & 19 & 18 & 27 & 20 & 23 & 23 & 28 & 26 \\
\hline Taiwan [15] & Taiwan National Nutrition and Health Survey & $\geq 19$ & 2608 & 12 & 17 & - & - & - & - & 6 & 13 & - \\
\hline Japan [12] & Population-based (DETECT 2) & $>35$ & 2016 & 8 & 10 & - & 3 & 3 & - & 8 & 11 & - \\
\hline China [16] & Two agricultural counties & $25-64$ & 18,630 & 5 & 12 & 8 & - & - & - & 4 & 11 & 7 \\
\hline
\end{tabular}

Men: men; W: women, ATP: National Cholesterol Education Program-Adult Treatment Panel III; WHO: World Health Organization, IDF: International Diabetes Federation.

has been suggested that the definition of MetS should exclude individuals with known cardiovascular disease [23]. The question of whether MetS should exclude diabetes and/or cardiovascular disease is clearly dependent on the expected purpose of MetS, i.e. whether MetS is used to predict cardiovascular diseases, diabetes, insulin resistance, or a combination of these conditions independent of conventional risk factors. While our cross-sectional study emphasizes that different definitions of MetS tend to classify different individuals as having MetS, the most important question remains to determine, based on longitudinal data, whether MetS predicts cardiovascular events above the risk factors that constitute the syndrome.

Our study has some limitations. First, we cannot exclude a healthy volunteer bias related to voluntary participation to the study, which could tend to underestimate the actual prevalence of MetS in the population. Second, we assessed insulin resistance based on HOMA-IR, which is only partially correlated with the gold standard (hyperinsulinemic euglycemic clamp), yet a valid proxy for insulin resistance $[30,31]$. Third, OGTT was only performed on participants unaware of having diabetes and who had FBG between 5.6 and $7.0 \mathrm{mmol} / \mathrm{l}$, hence a source of slight underestimation of diabetes. On the other hand, strengths of the study include the population-based design of the study, a fairly large sample size, and a broad panel of investigations that allowed us to directly compare the different MetS definitions.

In conclusion, this study contributes to mapping the prevalence of MetS worldwide, particularly with regards to the African region. The study also further contributes to the longstanding debate regarding the significance of MetS. The substantially different prevalence of MetS upon exclusion of individuals with diabetes underlies the need to clarify whether MetS is a tool for predicting cardiovascular disease, diabetes, insulin resistance or any other risk condition. These issues are further prompted by the finding, in our study, that the different considered MetS definitions identified, to a substantial extent, different individuals. Not withstanding a much needed unified definition of MetS, our findings in Seychelles emphasize the growing burden of lifestyle-related non-communicable diseases in countries in epidemiological transition including in the African region, consistent with the ongoing epidemic of obesity worldwide and in the Seychelles in particular.

\section{List of abbreviations}

ATP: National Cholesterol Education Program-Adult Treatment Panel III; WHO: World Health Organization; IDF: International Diabetes Federation; EGIR: European 
Group for the Study of Insulin Resistance; HDL-cholesterol: High density lipoprotein cholesterol; FBG: fasting blood glucose; HOMA-IR: homeostasis model assessment of insulin resistance; OGTT: oral glucose tolerance test.

\section{Competing interests}

The authors declare that they have no competing interests.

\section{Authors' contributions}

CK led the analysis of data and the write up of the manuscript; JW had a coordinating role in the conduct of the study and reviewed the manuscript; WR performed most of the blood analyses and reviewed the manuscript; FP participated in the study design and reviewed the manuscript; PB was the principal investigator of the study and actively participated in the data analysis and the write up of the manuscript.

\section{Acknowledgements}

The authors thank the Ministry of Health and Social Development, Republic of Seychelles, for continued support to epidemiological research for non communicable diseases. The authors also thank A. Chiolero and J. Jaunin for useful comments and advice.

\section{References}

I. Ford ES: Risks for all-cause mortality, cardiovascular disease and diabetes associated with the metabolic syndrome. A summary of the evidence. Diabetes Care 2005, 28:1769-78.

2. Kahn R: Metabolic syndrome-what is the clinical usefulness? Lancet 2008, 37 I(9628): I892-93.

3. Reaven GM: The metabolic syndrome: is this diagnosis necessary? Am J Clin Nutr 2006, 83(6): 1237-47.

4. Harzallah F, Alberti H, Ben Khalifa F: The Metabolic Syndrome in an Arab population: a first look at the new International Diabetes Federation criteria. Diabet Med 2006, 23:44I-44.

5. Ford ES: Prevalence of the Metabolic Syndrome Defined by the International Diabetes Federation Among Adults in the US. Diabetes Care 2005, 28:2745-49.

6. Aguilar-Salinas CA, Rojas R, Gómez-Pérez FJ, Valles V, Ríos-Torres JM, Franco A, Olaiz G, Rull JA, Sepúlveda J: High prevalence of metabolic syndrome in Mexico. Arch Med Res 2004, 35(I):76-8I.

7. Can AS, Bersot TP: Analysis of agreement among definitions of metabolic syndrome in non-diabetic Turkish adults: a methodological study. BMC Public Health 2007, 19:7(I):353.

8. Santos A-C, Barros $\mathrm{H}$ : Impact of metabolic syndrome definitions on prevalence estimates: a study in a Portuguese community. Diabetes Vasc Dis Res 2007, 4:320-78.

9. Boronat M, Chirino R, Varillas VF, Saavedra P, Marrero D, Fábregas $M$, Nóvoa FJ: Prevalence of the metabolic syndrome in the island of Gran Canaria: comparison of three major diagnostic proposals. Diabet Med 2005, 22( I 2): 175 I-56.

10. Hildrum B, Mykletun A, Hole T, Midthjell K, Dahl AA: Age-specific prevalence of the metabolic syndrome defined by the International Diabetes Federation and the National Cholesterol Education Program: the Norwegian HUNT 2 study. BMC Public Health 2007, 7:220.

II. Assmann G, Guerra R, Fox G, Cullen P, Schulte H, Willett D, Grundy $S M$ : Harmonizing the definition of the metabolic syndrome: comparison of the criteria of the Adult Treatment Panel III and the International Diabetes Federation in United States American and European populations. Am J Cardiol 2007, 99(4):54|-48.

12. Athyros VG, Ganotakis ES, Bathianaki M, Monedas I, Goudevenos IA, Papageorgiou AA: Awareness, treatment and control of the metabolic syndrome and its components: A Multicentre Greek Study. Hellenic J Cardiol 2005, 46:380-86.

13. Lee C, Huxley R, Woodward M, Zimmet P, Shaw J, Cho N, Kim H, Viali S, Tominaga M, Vistisen D, Borch-Johnsen K, Colagiuri S: Com- parisons of metabolic syndrome definitions in four populations of the Asia-Pacific region. Metab Syndr Relat Disord 2008, 6:37-46.

14. Choi KM, Kim SE, Kim YE, Choi DS, Baik SH, Lee J: Prevalence and cardiovascular disease risk of the metabolic syndrome using National Cholesterol Education Program and International Diabetes Federation definitions in the Korean population. Metabolism 2007, 56:552-8.

15. Deepa M, Farooq S, Datta M, Deepa R, Mohan V: Prevalence of metabolic syndrome using WHO, ATPIII and IDF definitions in Asian Indians: The Chennai Urban Rural Epidemiology Study (CURES-34). Diabetes Metab Res Rev 2007, 23(2):127-34.

16. Chen H-J, Pan W-H: Probable blind spot in the International Diabetes Federation definition of metabolic syndrome. Obesity 2007, I 5: 1096-I 100.

17. Feng $Y$, Hong $X$, Li Z, Zhang W, Jin D, Liu X, Zhang Y, Hu FB, Wei LJ, Zang T, $X u X, X u X$ : Prevalence of metabolic syndrome and its relation to body composition in a chinese rural population. Obesity 2006, I 4(II):2089-98.

18. Fezeu L, Balkau B, Kengne AP, Sobngwi E, Mbanya JC: Metabolic syndrome in a Sub-Saharan African setting: central obesity may be the key determinant. Atherosclerosis 2007, 193(1):70-76.

19. Alberti KG, Zimmet PZ, for the WHO Consultation: Definition, diagnosis and classification of diabetes mellitus and its complications. Part I: Diagnosis and classification of diabetes mellitus and its complications. Provisional report of a WHO consultation. Diabet Med 1998, 15:539-53.

20. Grundy SM, Cleeman JI, Daniels SR, Donato KA, Eckel RH, Franklin BA, Gordon DJ, Krauss RM, Savage PJ, Smith SC Jr, Spertus JA, Costa F, American Heart Association; National Heart, Lung and Blood Institute: Diagnosis and Management of the Metabolic Syndrome: An American Heart Association/National Heart, Lung and Blood Institute Scientific Statement. Circulation 2005, I I 2(I7):2735-52

21. Alberti KG, Zimmet PZ, Shaw J: The Metabolic Syndrome - A new worldwide definition. Lancet 2005, 366: 1059-62.

22. Yoon YS, Lee ES, Park C, Oh SW: The new definition of the metabolic syndrome by the international diabetes federation is less likely to identify metabolically abnormal but non-obese individuals than the definition by the revised national cholesterol education program: The Korean NHANES Study. Int J Obesity 2007, $31: 528-34$.

23. Gale EA: Should we dump the metabolic syndrome? Yes. BMJ 2008, 336:640.

24. Management \& Information Systems Division: Statistical abstracts. Victoria, Seychelles 2004.

25. Bovet P, Shamlaye C, Kitua A, Riesen WF, Paccaud F, Darioli R: High prevalence of cardiovascular risk factors in the Seychelles (Indian Ocean). Arterioscler Thromb I99I, I I(6): 1730-36.

26. Bovet P, Shamlaye C, Gabriel A, Riesen W, Paccaud F: Prevalence of cardiovascular risk factors in a middle-income country and estimated cost of a treatment strategy. BMC Public Health 2006, 19(6):9.

27. Faeh D, William J, Tappy L, Ravussin E, Bovet P: Prevalence, awareness and control of diabetes in the Seychelles and relationship with excess body weight. BMC Public Health 2007, 7:163.

28. Pruijm MT, Madeleine G, Riesen WF, Burnier M, Bovet P: Prevalence of microalbuminuria in the general population of Seychelles and strong association with diabetes and hypertension independent of renal markers. J Hypertens 2008, 26(5):87I-77.

29. Matthews DR, Hosker JP, Rudenski AS, Naylor BA, Treacher DF, Turner RC: Homeostasis model assessment: insulin resistance and $B$ cell function from plasma glucose and insulin concentrations in man. Diabetologia 1985, 28:4I2-19.

30. Bonora E, Targher G, Alberiche M, Bonadonna RC, Saggiani F, Zenere MB, Monauni T, Muggeo M: Homeostasis model assessment closely mirrors the glucose clamp technique in the assessment of insulin sensitivity: studies in subjects with various degrees of glucose tolerance and insulin sensitivity. Diabetes Care 2000, 23(I):57-63.

31. Ikeda $Y$, Suehiro T, Nakamura T, Kumon $Y$, Hashimoto K: Clinical significance of the insulin resistance index as assessed by homeostasis model assessment. Endocr J 200I, 48:8I-86.

32. Ahmad OB, Boschi-Pinto C, Lopez AD, Murray CJL, Lozano R, Inoue M: Age standardization of rates: A new WHO standard. In 
Global Program on Evidence for Health Policy; Paper Series No 3 I World Health Organization, Geneva; 2005.

33. Balkau B, Charles MA: Comment on the provisional report from the WHO consultation. European Group for the Study of Insulin Resistance (EGIR). Diabet Med 1999, 16:442-43.

34. Bochud M, Nussberger J, Bovet P, Maillard MR, Elston RC, Paccaud F, Shamlaye C, Burnier M: Plasma aldosterone is independently associated with the metabolic syndrome. Hypertension 2006, 48(2):239-45

35. Cameron AJ, Shaw JE, Zimmet PZ: The metabolic syndrome: prevalence in worldwide populations. Endocrinol Metab Clin North Am 2004, 33(2):35I-75.

36. Benetos A, Thomas F, Pannier B, Bean K, Jégo B, Guize L: All-Cause and Cardiovascular Mortality Using the Different Definitions of Metabolic Syndrome. Am J Cardiol 2008, I 02(2): |88-9|.

37. Nilsson PM, Engstrom G, Hedblad B: The metabolic syndrome and incidence of cardiovascular disease in non-diabetic subjects-a population based study comparing three different definitions. Diabet Med 2007, 24(5):464-72.

38. Balkau B, Charles MA, Drivsholm T, Borch-Johnsen K, Wareham N Yudkin JS, Morris R, Zavaroni I, van Dam R, Feskins E, Gabriel R, Diet M, Nilsson P, Hedblad B, European Group For The Study Of Insulin Resistance (EGIR): Frequency of the WHO metabolic syndrome in European cohorts, and an alternative definition of an insulin resistance syndrome. Diabetes Metab 2002, 28(5):364-76

39. Hu G, Qiao Q, Tuomilehto J, Balkau B, Borch-Johnsen K, Pyorala K: Prevalence of the metabolic syndrome and its relation to allcause and cardiovascular mortality in nondiabetic European men and women. Arch Intern Med 2004, 164:1066-76.

Publish with Biomed Central and every scientist can read your work free of charge

"BioMed Central will be the most significant development for disseminating the results of biomedical research in our lifetime. "

Sir Paul Nurse, Cancer Research UK

Your research papers will be:

- available free of charge to the entire biomedical community

- peer reviewed and published immediately upon acceptance

- cited in PubMed and archived on PubMed Central

- yours - you keep the copyright 